\title{
Role of diffusion-weighted MRI in characterization of mediastinal masses
}

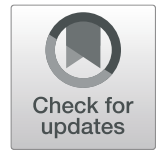

\author{
Tarek Ahmed Raafat ${ }^{1 *}$ (D), Shimaa Mohamed Ahmed², Emam Mohamed Abo Seif², \\ Hisham Samir Wahba Mikhael ${ }^{1}$ and Ahmed Sayed Awad $^{3}$ (1)
}

\begin{abstract}
Background: Diffusion MR imaging (DWI) is a widely available non-invasive non-contrast functional MR imaging technique with short acquisition time. It helps in the analysis of tissue characteristics based on the diffusion of water protons within the tissue. Quantitative assessment of a mass is possible by calculating its apparent diffusion coefficient (ADC) value which is inversely correlated with tissue cellularity. So, DWI has diagnostic potential to distinguish benign from malignant tumors because of the tendency of the latter to show lower ADC values and more restricted diffusion. The aim of our work is to evaluate the use of DWI and ADC value measurement in differentiation between benign and malignant mediastinal tumors.

Results: This study included 44 cases of mediastinal masses: 27 males and 17 females. The mean ADC value of malignant mediastinal lesions was significantly lower than the mean ADC value of benign mediastinal lesions, with mean ADC $1.39 \pm 0.26$ in benign mediastinal lesions and mean ADC $0.86 \pm 0.35$ in malignant mediastinal lesions. This study also revealed that the cut-off threshold of ADC value for the differentiation between malignant and benign lesions was $1.11 \times 10^{-3} \mathrm{~mm}^{2} / \mathrm{s}$, with an area under ROC curve of 0.93 . The sensitivity and specificity of our cutoff ADC values were $90.9 \%$ and $100 \%$, with $100 \%$ positive predictive value and $76.9 \%$ negative predictive value.
\end{abstract}

Conclusion: DWI with calculation of ADC value is functional MR imaging technique used in the analysis of tissue characteristics and quantitative assessment of a mediastinal mass. So, it can distinguish benign from malignant tumors because of the tendency of the malignant lesions to show more restricted diffusion and lower ADC values.

Keywords: Diffusion MRI-characterization-mediastinal masses

\section{Background}

The differential diagnosis of mediastinal lesions includes a wide variety of neoplastic, congenital, vascular, and lymphatic etiology [1]. The location and composition of the mediastinal lesions are essential to limit the diagnostic possibilities [2].

Computed tomography $(\mathrm{CT})$ is considered the primary modality of choice for morphological evaluation of mediastinal tumors. Magnetic resonance imaging (MRI) is considered a second-line test. Also, 18F-fluorodeoxyglucose positron emission tomography/CT (18F-FDG-PET/CT) is

\footnotetext{
*Correspondence: tarek2005_8@yahoo.com

'Radiology Department, National Cancer Institute-Cairo University, Giza, Egypt

Full list of author information is available at the end of the article
}

widely used for assessing cell metabolism and metabolic activity of the lesions pre and post-therapy [3].

Nowadays, the role of MR imaging expands due to its high soft-tissue contrast. It is better than CT in differentiation between cystic and solid masses, identification of cystic and solid components within complex lesions, and distinguishing thymic hyperplasia and normal thymus from thymic neoplasm. Also, MRI can give a better assessment of the relations of the lesion with the pericardium, heart, spinal cord, and vascular structures [2].

With the advances in MR systems, diffusion-weighted imaging (DWI) of the chest has become possible with fast imaging time that minimizes the effect of respiration and cardiac movement. DWI helps in the analysis of tissue characteristics based on the diffusion of water 
protons within the tissue. Quantitative assessment of a mass is possible by calculating its apparent diffusion coefficient (ADC) value which is inversely correlated with tissue cellularity. So, DWI has diagnostic potential to distinguish benign from malignant tumors because of the tendency of the latter to show lower ADC values and more restricted diffusion $[2,4]$. Also, it is useful besides other modalities in differentiating lymphoma from sarcoidosis in mediastinal and hilar lymphadenopathy [5]. Moreover, DWI is used to characterize lung lesions, to predict tumor invasiveness, to detect tumors in collapsed lungs, and for nodal staging of lung cancer [6]. Quantitative analysis of DWI also enables differentiation of lymph nodes with and without metastasis [7]. Potential future applications of DWI in malignancies include monitoring the treatment response after chemotherapy or radiation [6].

The primary objective of our study was to evaluate the potential of DWI and calculated ADC value to characterize mediastinal lesions and to differentiate between benign and malignant tumors. So, it can enhance the non-invasive approaches by which patients can be diagnosed and avoid unnecessary intervention.

\section{Methods}

The Institutional Review Board of our Radiology Department approved the design of the study and the use of clinical data. Written consent was obtained from the patients or their parents prior to the procedures.

This study included 44 cases of mediastinal masses: 27 males and 17 females with mean age of 34.8 (range, 1-69 years). All were primarily diagnosed by CT. Cases were referred from oncology and chest departments for MRI assessment between February 2018 and January 2020. The complaints varied between dyspnea, chest pain, cough, hemoptysis, dysphagia, fatigue, and loss of weight. The flow chart of our study is illustrated in Fig. 1.

\section{Inclusion criteria}

Patients with mediastinal masses were diagnosed by CT.

\section{Exclusion criteria}

General criteria of contra-indication to MRI as patients with pacemaker, cochlear implants, cerebral aneurysm clips, and ocular metallic foreign body.

All patients were subjected to the following:

- Proper clinical evaluation

- Revision of their laboratory investigations including complete blood picture, random blood sugar, and liver and kidney functions

- Revision of their CT studies of the chest

- MRI examination of the chest including diffusion sequences
- Histopathological assessment

\section{MRI protocol}

MRI was performed on 1.5 Tesla closed magnet unit (Achieva; Philips Medical Systems, Best, The Netherlands) using a 16-channel phased-array torso coil (Sense XL Torso; Philips Healthcare). To obtain the highest quality MRI, infants and children were given sedation medications through an intravenous (IV) line by a specialized anesthetist. Respiratory gating has been used. The MR scanning sequences are T1W1, T2WI, T2 STIR and DWI, ADC map, and quantitative DWI analysis (ADC measurement).

- T1WI was obtained with the spin-echo sequence with the following parameters: repetition time/echo time, $10 \mathrm{~ms} / 5 \mathrm{~ms}$; number of excitations, 2; direction of frequency encoding, $\mathrm{R} / \mathrm{L}$; section thickness, $8 \mathrm{~mm}$; gap, $0.5 \mathrm{~mm}$; field of view, $36-40 \mathrm{~cm}$; matrix, $288 \times$ 224.

- T2WI was obtained with the following parameters: repetition time/echo time, $664 \mathrm{~ms} / 80 \mathrm{~ms}$; number of excitations, 3; direction of frequency encoding, R/L; section thickness, $8 \mathrm{~mm}$; gap, $1.5 \mathrm{~mm}$; field of view, $36-40 \mathrm{~cm}$; matrix, $288 \times 224$.

- T2 STIR was obtained with the following parameters: repetition time/echo time, $1.6 \mathrm{~ms} / 20 \mathrm{~ms}$; number of excitations, 3; direction of frequency encoding, R/L; section thickness, $10 \mathrm{~mm}$; gap, $1 \mathrm{~mm}$; field of view, $36-40 \mathrm{~cm}$; matrix, $288 \times 224$.

- DWI is typically acquired in a transverse plane, using three $b$ values; low $\left(0-50 \mathrm{~s} / \mathrm{mm}^{2}\right)$, intermediate $\left(500 \mathrm{~s} / \mathrm{mm}^{2}\right)$, and high $b$ value $\left(1000 \mathrm{~s} / \mathrm{mm}^{2}\right)$. The typical slice thickness is $4-9 \mathrm{~mm}$ with an interslice gap of $0-1.5 \mathrm{~mm}$, and the number of excitations ranges from 1 to 10 .

- ADC map images and quantitative DWI analysis (ADC measurement).

\section{MR data evaluation and analysis Lesion assessment}

Qualitative assessment Each lesion was evaluated for its location, extent, size, and relation to adjacent structures. Its signal intensity was evaluated in all pulse sequences T1 WI, T2 WI, STIR WI, and its signal in DWI and ADC maps were compared.

Quantitative assessment ADCs values were calculated from the ADC maps which were constructed from $b=0$ and $b=1000 \mathrm{~s} / \mathrm{mm}^{2}$ values. A ROI (region of interest) was drawn within areas visually judged to be the most restricted, and the size of ROI was kept as large as possible on the ADC map avoiding the macroscopic 


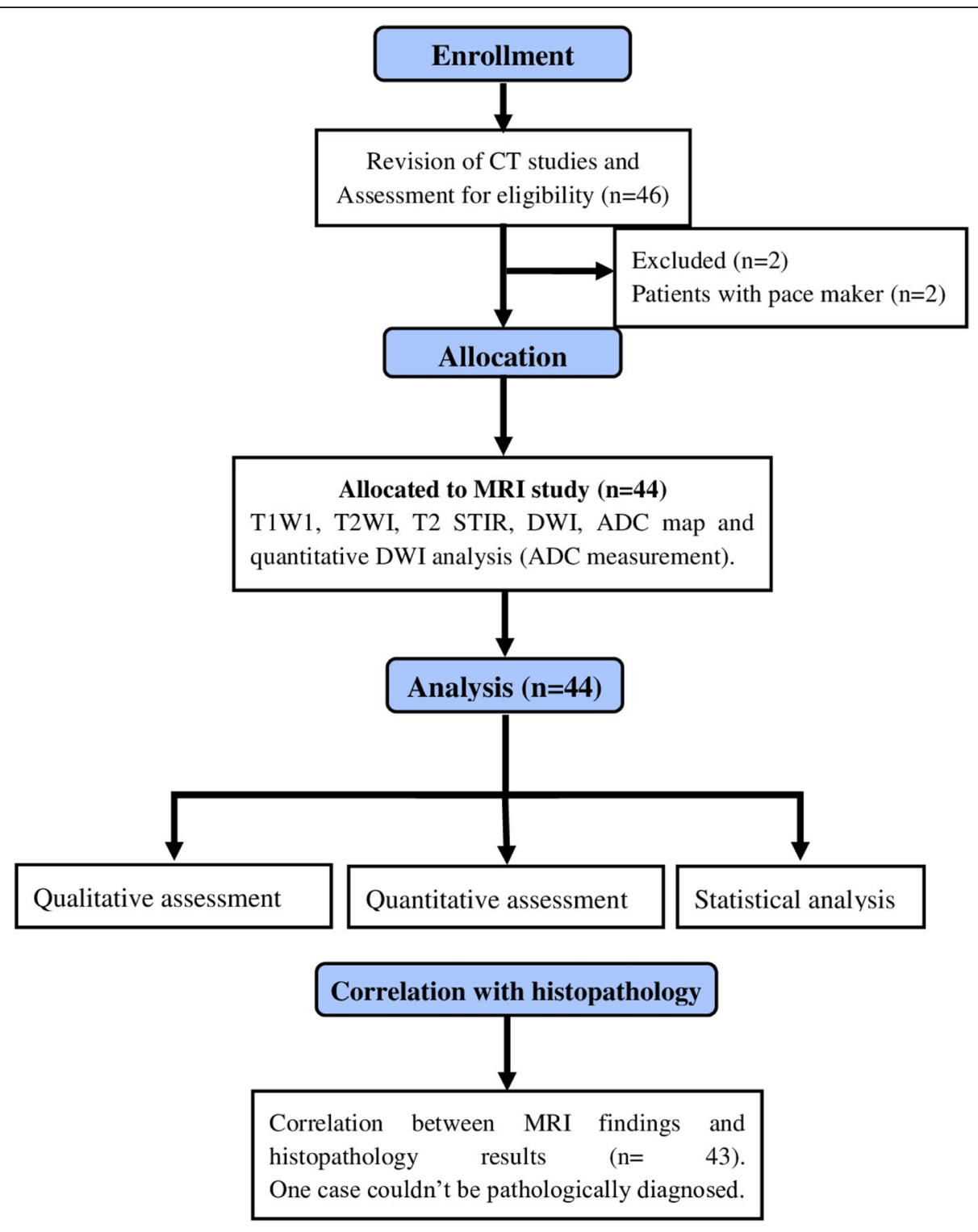

Fig. 1 Consort flowchart

necrosis and major blood vessel in the light of the conventional images. The average of three measurements was recorded as the final result.

\section{Associated findings}

The following findings were evaluated in MRI, DWI, and ADC map:

- Presence of hilar or mediastinal lymphadenopathy. In the assessment of lymph nodes, only lymph nodes appropriate to criteria were measured for ADC value. Lesions containing large amounts (more than $50 \%$ of total size) of necrosis or calcification were excluded.
Other associated MRI findings were taken into consideration:

- Pleural or pericardial collections

- Presence of other chest lesions as chest wall lesions or breast masses

- Presence of upper abdominal lesions

\section{Histopathological diagnosis}

The choice of method of tissue sampling/biopsy depends upon both lesion accessibility and patients' general condition. Tru cut CT-guided core biopsies were done in 29 patients while bronchoscopic biopsies were obtained in 14 patients. 


\section{Statistical analysis}

ADC was statistically described in terms of mean \pm standard deviation ( $\pm \mathrm{SD})$, median, and range. Comparison of ADC between benign and malignant mediastinal masses. Accuracy of ADC in differentiating benign from malignant lesions using the terms sensitivity and specificity. Receiver operator characteristic (ROC) analysis was used to determine the optimum cut off value. $P$ values of less than 0.05 were considered statistically significant. All statistical calculations were done using computer program SPSS (Statistical Package for the Social Science; SPSS Inc., Chicago, IL, USA) release 23.

\section{Results}

This study included 44 cases of mediastinal masses: 27 males and 17 females with mean age of 34.8 (range, 169 years) (Table 1). There were 6 patients with multiple mediastinal lesions related to the same pathology, so we made our results on the number of patients, not the masses.

The study included 34 malignant cases (77.3\%) and 10 benign cases $(22.7 \%)$. The pathological diagnosis, their number/percentage, and corresponding mean ADC value are shown in Table 2.

Most of the cases (38 cases) have a single mediastinal lesion which represents $86.4 \%$ with majority of lesions (15 cases) are located in the anterior mediastinum which represents $34.1 \%$. The description of the studied cases regarding site in mediastinum, lesions' dimensions, and number of lesions are presented in Table 3.

Regarding the MRI signal intensity, in 41 cases, the masses showed heterogeneous signal intensity representing 93.2\% while in 3 cases, the masses showed homogenous signal intensity representing $6.8 \%$. There were 12 cases that showed an isointense signal in DWI (facilitated diffusion) representing 27.3\%, while 32 cases showed high signal (restricted diffusion) representing 72.7\%. There was a low signal in the ADC map in 35 cases representing $79.5 \%$, while 8 cases were with mixed signal representing $18.2 \%$ and only one case with a high signal representing 2.3\% (Table 4).

There was no statistically significant difference found between the malignant and benign lesions regarding the

Table 1 Description of the studied cases regarding age, sex, and nature of lesions

\begin{tabular}{lll}
\hline & & Total no. $\mathbf{4 4 4}$ \\
\hline Age (years) & Mean & 34.8 \\
& Range & $1-69$ \\
Sex & Females & $17(38.6 \%)$ \\
& Males & $27(61.4 \%)$ \\
Benign/malignant & Benign & $10(22.7 \%)$ \\
& Malignant & $34(77.3 \%)$ \\
\hline
\end{tabular}

number of lesions, their site, and lesion signal, while there was a highly significant difference regarding ADC map and DWI. One hundred percent of the benign lesions showed isointense signal in DWI (facilitated diffusion), with $80 \%$ showed mixed signal intensity with ADC map, while $94 \%$ of malignant lesions showed high signal in DWI (restricted diffusion), with $97.1 \%$ showed low signal in ADC map (Table 5).

The mean ADC value for all cases was $0.98 \pm 0.40 \times$ $10^{-3} \mathrm{~mm}^{2} / \mathrm{s}$. The mean ADC value for malignant lesions was $0.86 \pm 0.35 \times 10^{-3} \mathrm{~mm}^{2} / \mathrm{s}$, while the mean ADC for benign lesions was $1.39 \pm 0.26 \times 10^{-3} \mathrm{~mm}^{2} / \mathrm{s}$. A comparison between the mean ADC value of the benign and malignant mediastinal lesions was highly significant with $P$ value $<0.001$ (Table 5).

The ROC curve (Fig. 2) shows that the best cut off point to predict malignant tumors was found $\leq 1.11$ with a sensitivity of $90.9 \%$ and specificity of $100 \%$ with $100 \%$ positive predictive value and $76.9 \%$ negative predictive value.

\section{MRI findings in cases pathologically proven as bronchogenic carcinoma}

This group included 10/44 patients diagnosed as bronchogenic carcinoma (22.8\%) (Fig. 3). Six male and four female patients with mean age $55.20 \pm 12.59$ years (range, 32-69 years). Nine cases showed soft tissue mass lesions with restricted diffusion evident by high signal intensity in DWI, low signal intensity in ADC map, and low ADC values, whereas only one case showed an isointense signal in DWI. The cases showed ADC value ranging from 0.56 up to 0.99 (mean ADC $0.79 \pm 0.14$ ) $\times$ $10^{-3} \mathrm{~mm}^{2} / \mathrm{s}$. Quantitative analysis has also been used to assess associated mediastinal/hilar lymph nodes. Four out of ten patients (40\%) had associated lymphadenopathy. Lymph nodes were localized and defined as follows: 2 prevascular, 2 right hilar, 1 paraaortic, 1 subaortic, 1 right paraesophageal, 1 right upper paratracheal, and 1 right lower pre tracheal. All lymph nodes assessed showed restricted diffusion with mean ADC value $0.70 \pm$ $0.26 \times 10^{-3} \mathrm{~mm}^{2} / \mathrm{s}$, (range $0.43-1.10$ ).

\section{MRI findings in cases with hilar/mediastinal lymphadenopathy}

Our study involved the evaluation of 8 patients with mediastinal/hilar lymphadenopathy; 7 male patients pathologically proven as lymphoma with age range 14-63 years (Fig. 4). The remaining one was a female patient 60 years old diagnosed as cancer breast with mediastinal lymphadenopathy.

Lymph nodes in lymphoma cases localized and defined as follows: 5 amalgamated anterior mediastinal masses, 1 right hilar, 1 right paratracheal, 1 right prevascular, and 1 left prevascular. Lymph nodes in lymphoma showed 
Table 2 Pathological findings and their mean ADC values

\begin{tabular}{llll}
\hline Diagnosis & No. & $\%$ & Mean ADC value \\
\hline Bronchogenic carcinoma & 10 & 22.8 & $0.79 \pm 0.14 \times 10^{-3} \mathrm{~mm}^{2} / \mathrm{s}$ \\
Lymphoma & 7 & 15.9 & $0.84 \pm 0.43 \times 10^{-3} \mathrm{~mm}^{2} / \mathrm{s}$ \\
Germ cell tumor & 3 & 6.8 & $1.058 \pm 0.921 \times 10^{-3} \mathrm{~mm}^{2} / \mathrm{s}$ \\
Liposarcoma & 2 & 4.5 & $1.05 \pm 0.63 \times 10^{-3} \mathrm{~mm}^{2} / \mathrm{s}$ \\
Metastatic nodes from breast cancer & 1 & 2.3 & $1.033 \pm 0.3 \times 10^{-3} \mathrm{~mm}^{2} / \mathrm{s}$ \\
Metastatic nodes from RCC & 1 & 2.3 & $1.033 \pm 0.3 \times 10^{-3} \mathrm{~mm}^{2} / \mathrm{s}$ \\
Synovial sarcoma & 1 & 2.3 & $0.9 \times 10^{-3} \mathrm{~mm}^{2} / \mathrm{s}$ \\
Undifferentiated carcinoma & 2 & 4.5 & $0.9 \times 10^{-3} \mathrm{~mm}^{2} / \mathrm{s}$ \\
Neuroendocrinal tumor & 2 & 4.6 & $1.5 \times 10^{-3} \mathrm{~mm}^{2} / \mathrm{s}$ \\
Neurogenic tumor & 6 & 13.6 & $1.08 \pm 0.32 \times 10^{-3} \mathrm{~mm}^{2} / \mathrm{s}$ \\
Rhabdomyosarcoma & 1 & 2.3 & $0.5 \times 10^{-3} \mathrm{~mm}^{2} / \mathrm{s}$ \\
Thymic tumor & 5 & 11.4 & $1.08 \pm 0.32 \times 10^{-3} \mathrm{~mm}^{2} / \mathrm{s}$ \\
Bronchogenic cyst & 1 & 2.3 & $1.7 \times 10^{-3} \mathrm{~mm}^{2} / \mathrm{s}$ \\
Paracardiac cyst & 1 & 2.3 & $1.8 \times 10^{-3} \mathrm{~mm}^{2} / \mathrm{s}$ \\
Not diagnosed & 1 & 2.3 & $0.7 \times 10^{-3} \mathrm{~mm}^{2} / \mathrm{s}$ \\
\hline
\end{tabular}

significantly increased signal in DWI and significant low signal in the ADC map, except for one case that showed a faint high signal in DWI and high signal in ADC map due to necrosis. The mean ADC for lymphoma was $(0.84 \pm 0.43) \times 10^{-3} \mathrm{~mm}^{2} / \mathrm{s}$, with range $0.50-1.80$. Associated MRI findings were seen in 2 cases included pleural effusion in 1 case and 2 chest wall masses in 1 case.

Lymph nodes in breast cancer cases were localized as follows: right and left prevascular, right paratracheal, right paraesophageal, and retro-sternal. They showed a significantly increased signal in DWI and a significant low signal in the ADC map.

\section{MRI findings in cases pathologically proven as neurogenic} tumor

This study included 6 cases, three males and three females with age range 30-52 years diagnosed as neurogenic tumor, pathologically proven as follows: 2 cases neurofibroma, 2 cases ganglioneuroma, 1 case malignant schwannoma, and 1 case ganglioneuroblastoma.

Malignant schwannoma and ganglio-neuroblastoma showed high signal (restricted diffusion) in DWI and low signal in the ADC map with low ADC values. Ganglioneuroma case showed an isointense signal in DWI and mixed signals in the ADC map. Neurofibroma cases

Table 3 Description of the studied cases regarding site in mediastinum, lesions' dimensions, and number of lesions

\begin{tabular}{|c|c|c|}
\hline & & Total no. $=44$ \\
\hline \multirow[t]{8}{*}{ Site in mediastinum } & Anterior & $15(34.1 \%)$ \\
\hline & Anterior and middle & $1(2.3 \%)$ \\
\hline & Anterior and posterior & $2(4.5 \%)$ \\
\hline & Middle & $13(29.5 \%)$ \\
\hline & Posterior & $8(18.2 \%)$ \\
\hline & Superior & $2(4.5 \%)$ \\
\hline & Superior and anterior & $1(2.3 \%)$ \\
\hline & Superior and middle & $2(4.5 \%)$ \\
\hline Length & Mean \pm SD (range) & $6.99 \pm 3.14(1.3-14.8)$ \\
\hline Width & Mean \pm SD (range) & $7.10 \pm 3.66(1.6-19.4)$ \\
\hline \multirow[t]{5}{*}{ Number of mediastinal lesions } & 1 & $38(86.4 \%)$ \\
\hline & 2 & $2(4.5 \%)$ \\
\hline & 3 & $1(2.3 \%)$ \\
\hline & 4 & $2(4.5 \%)$ \\
\hline & 5 & $1(2.3 \%)$ \\
\hline
\end{tabular}


Table 4 Signal intensity of the studied cases by MR sequences, DW, and ADC

\begin{tabular}{llll}
\hline & & No. & \% \\
\hline Signal intensity & Heterogeneous & 41 & 93.2 \\
& Homogeneous & 3 & 6.8 \\
DWI & Facilitated & 12 & 27.3 \\
& Restricted & 32 & 72.7 \\
ADC map & Low signal & 35 & 79.5 \\
& High signal & 1 & 2.3 \\
& Mixed signal & 8 & 18.2 \\
\hline
\end{tabular}

showed an isointense signal in DWI and patchy low signals in the ADC map. The low ADC signal likely attributed to that the neurofibromas are cellular tumors that show a mixture of Schwann cells, neuronal axons, fibroblasts, mast cells, and collagen. All neurogenic tumor cases showed ADC values ranging from 0.55 to 1.49 , with mean ADC $(1.08 \pm 0.32) \times 10^{-3} \mathrm{~mm}^{2} / \mathrm{s}$. In the malignant neurogenic tumors, the ADC value was $<1.1 \times$ $10^{-3} \mathrm{~mm}^{2} / \mathrm{s}$; while in the benign neurogenic tumors, it was $\mathrm{ADC}>1.3 \times 10^{-3} \mathrm{~mm}^{2} / \mathrm{s}$.

\section{MRI findings in cases pathologically proven as thymic origin}

This study included 5 cases, three females and two males with age range $22-60$ years. They were pathologically diagnosed as follows: 1 case of thymoma, 2 cases thymic cancer, 1 case of prominent thymus, and 1case of mature thymic tissue. Thymic cancer and thymoma cases showed restricted diffusion in DWI, and low signal in the ADC map, with low ADC values. In this study, the mean ADC value for thymic tumors was $1.08 \pm 0.32 \times$ $10^{-3} \mathrm{~mm}^{2} / \mathrm{s}$.

\section{Other cases}

- 3 cases of germ cell tumor with age range 1-17 years, were pathologically diagnosed as follows:

Seminoma (2 cases), showing restricted diffusion with DWI, and low signal with ADC map, with low ADC values.

Teratoma (1 case), showing a faint high signal with DWI, and variable signals with ADC map, with higher ADC value (Fig. 5).

- 2 cases of liposarcoma (Fig. 6) having age 60 and 68 years presented with heterogeneous mediastinal masses, showing restricted diffusion with DWI, and low signal with ADC map, with low ADC values.

- 2 cases of undifferentiated carcinoma having age 55 and 66 years showing heterogeneous mediastinal masses, with restricted diffusion with DWI, and low signal with ADC map, with low ADC values $(0.9 \times$ $\left.10^{-3} \mathrm{~mm}^{2} / \mathrm{s}\right)$.

- 2 cases of neuroendocrinal tumor, one of them neuroendocrinal carcinoma, having age 66 years (Fig. 7) showing restricted diffusion with DWI, and low signal with ADC map, with low ADC value $\left(0.9 \times 10^{-3} \mathrm{~mm}^{2} / \mathrm{s}\right)$. The second case is a carcinoid tumor having age 57 years showing faint high signal with DWI, and mixed signals in ADC map with ADC value $\left(1.5 \times 10^{-3} \mathrm{~mm}^{2} / \mathrm{s}\right)$.

- One case of the following:

- Bronchogenic cyst having age 32 years presented with homogeneous posterior mediastinal mass, showing a faint high signal with DWI, and variable signal with ADC map, with $\mathrm{ADC}$ value $\left(1.7 \times 10^{-3}\right.$ $\left.\mathrm{mm}^{2} / \mathrm{s}\right)$.

Table 5 Comparison between benign and malignant tumors regarding signal homogeneity or heterogeneity, DWI, ADC map, and ADC value

\begin{tabular}{|c|c|c|c|c|c|c|c|c|}
\hline & & \multicolumn{2}{|c|}{ Benign } & \multicolumn{2}{|c|}{ Malignant } & \multirow[t]{2}{*}{ Test value $^{a}$} & \multirow[t]{2}{*}{$P$ value } & \multirow[t]{2}{*}{ Sig. } \\
\hline & & No. & $\%$ & No. & $\%$ & & & \\
\hline \multirow[t]{2}{*}{ Lesion } & Heterogeneous & 8 & 80 & 33 & 97.1 & 3.539 & 0.060 & NS \\
\hline & Homogeneous & 2 & 20 & 1 & 2.9 & & & \\
\hline \multirow[t]{2}{*}{ DWI } & Facilitated & 10 & 100 & 2 & 5.9 & 34.510 & 0.000 & HS \\
\hline & Restricted & 0 & 0 & 32 & 94.1 & & & \\
\hline \multirow[t]{3}{*}{ ADC map } & Low signal & 2 & 20 & 33 & 97.1 & 33.263 & 0.000 & HS \\
\hline & High signal & 0 & 0 & 1 & 2.9 & & & \\
\hline & Mixed signal & 8 & 80 & 0 & 0.0 & & & \\
\hline ADC value $\times\left(10^{-3} \mathrm{~mm}^{2} / \mathrm{s}\right)$ & Mean \pm SD & \multicolumn{2}{|c|}{$1.39 \pm 0.26$} & \multicolumn{2}{|c|}{$0.86 \pm 0.35$} & $-4.360^{\mathrm{b}}$ & 0.000 & HS \\
\hline
\end{tabular}

NS non-significant, HS highly significant

${ }^{a}$ Chi-square test

${ }^{\mathrm{b}}$ Independent $t$ test 


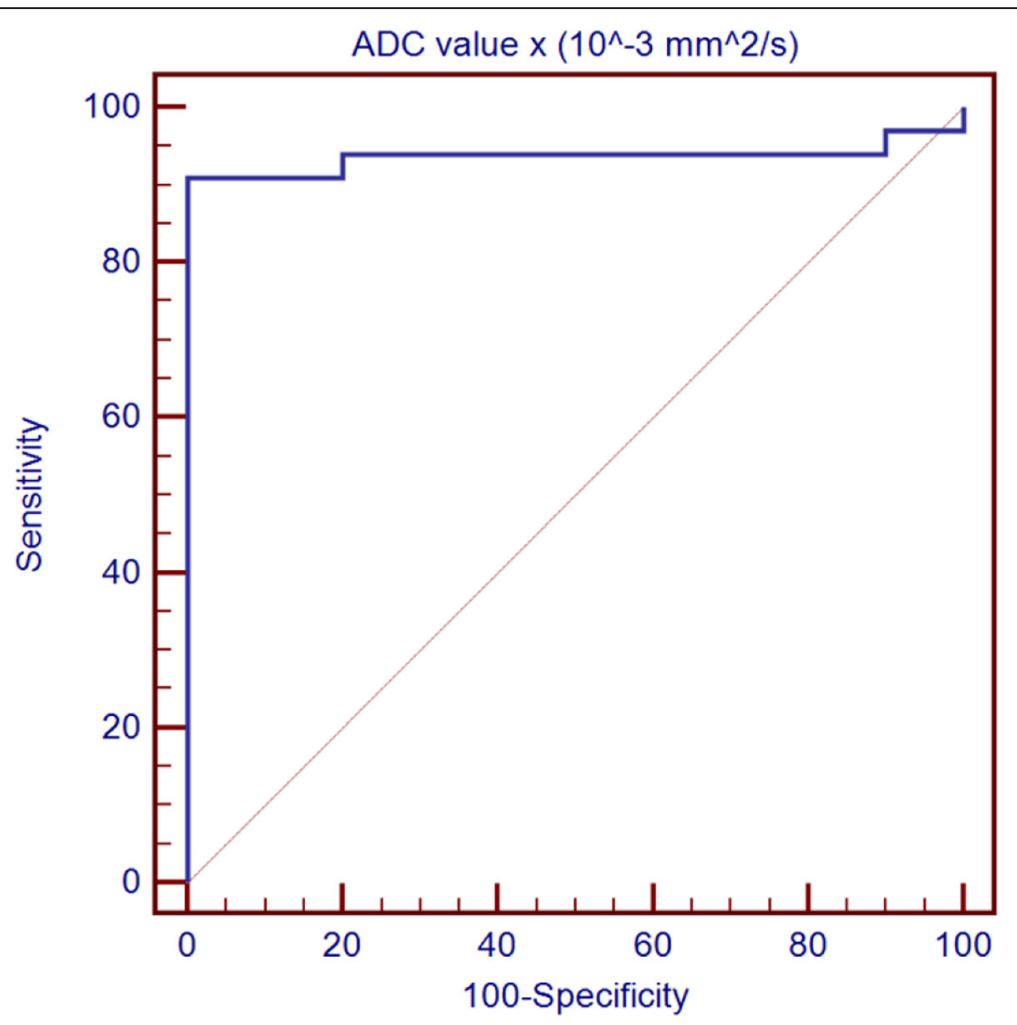

Fig. 2 Receiver operating characteristic curve (ROC) for the predictive value of ADC in differentiation between benign and malignant tumors

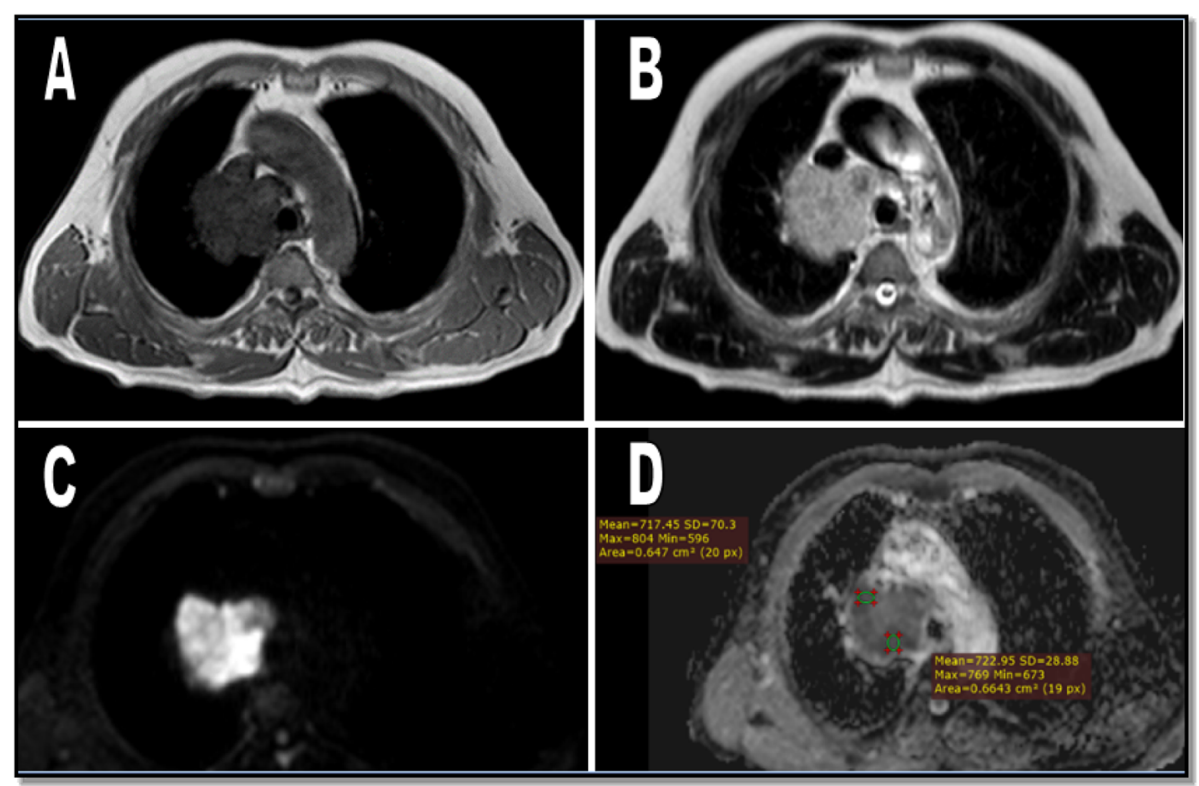

Fig. 3 Case of undifferentiated small cell lung cancer. A 69-year-old male presented with chest pain. MRI chest (a) axial T1WI, (b) axialT2WI, (c) DWI, (d) ADC map showing right side mediastinal soft tissue mass eliciting low signal in T1WI, high signal in T2WI and showing restricted diffusion (high signal on DWI and low signal on ADC map) with ADC value $0.7 \times 10^{-3} \mathrm{~mm}^{2} / \mathrm{s}$ 


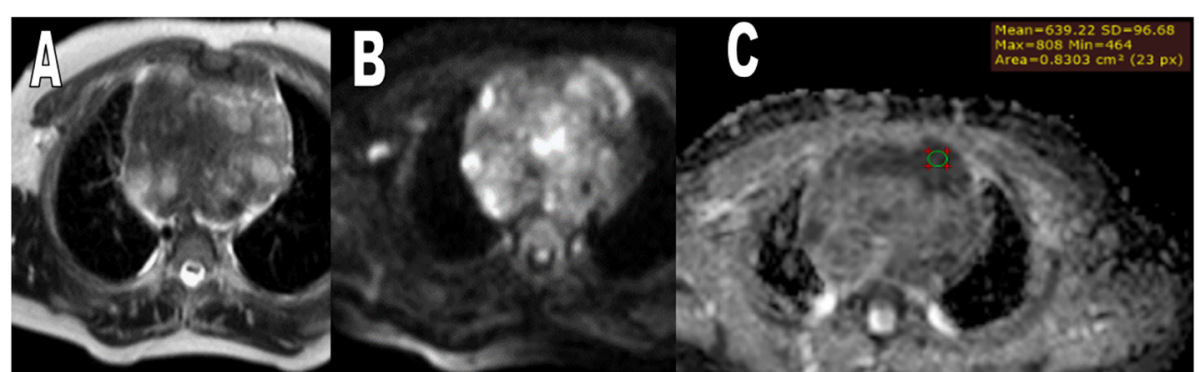

Fig. 4 Case of non-Hodgkin lymphoma. A 14-year-old male patient presenting with fatigue and loss of weight. MRI chest (a) axial T2Wl, (b) axial DWI, (c) ADC map showing anterior mediastinal prevascular, right and left paratracheal amalgamated lymph nodes eliciting intermediate signal on T2 Wl, patchy high signal on DWI, and low signal on ADC map (restricted diffusion). The mean ADC value was about $0.6 \times 10^{-3} \mathrm{~mm}^{2} / \mathrm{s}$

- Paracardiac cyst having age 40 years presented with homogeneous middle mediastinal mass, showing faint high signal with DWI, and variable signal with ADC map, with ADC value $\left(1.8 \times 10^{-3} \mathrm{~mm}^{2} / \mathrm{s}\right)$.

- Rhabdomyosarcoma having age 11 years presented with heterogeneous posterior mediastinal mass, showing restricted diffusion with DWI, and low signal with ADC map, with low ADC value $(0.5 \times$ $\left.10^{-3} \mathrm{~mm}^{2} / \mathrm{s}\right)$.

- Synovial sarcoma having age 25 years presented with heterogeneous middle mediastinal mass, showing restricted diffusion with DWI, and low signal with ADC map, with low ADC value $\left(0.9 \times 10^{-3} \mathrm{~mm}^{2} / \mathrm{s}\right)$.

- Metastatic renal cell carcinoma having age 42 years presented with heterogeneous anterior mediastinal mass, showing restricted diffusion with DWI, and low signal with ADC map.

- Only one case could not be pathologically diagnosed, but it was presented with heterogeneous anterior mediastinal mass, showing restricted diffusion with DWI, and low signal with ADC map, with low ADC value $\left(0.7 \times 10^{-3} \mathrm{~mm}^{2} / \mathrm{s}\right)$.
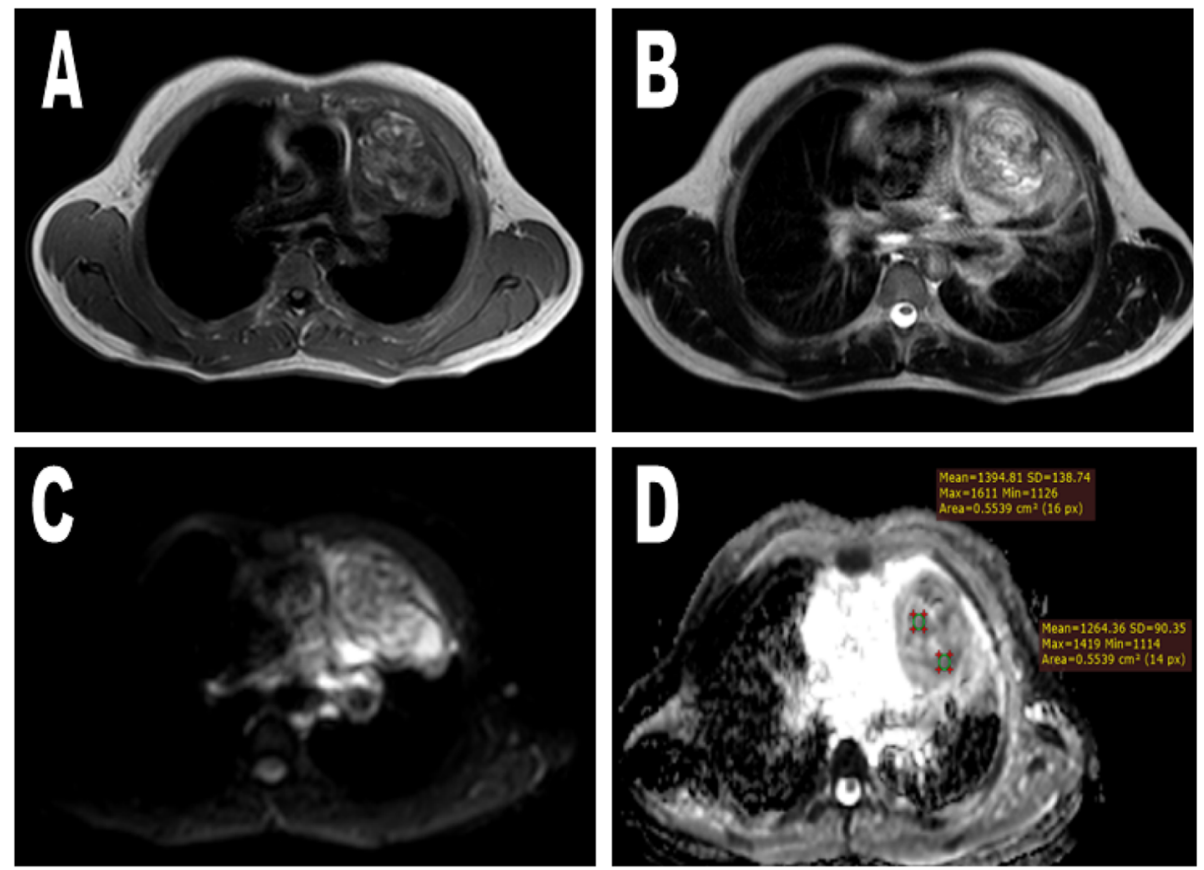

Fig. 5 Case of teratoma. A 14-year-old male patient presenting with dyspnea. (a) axial T1WI, (b) axial T2WI, (c) DWI, (d) ADC map showing mediastinal soft tissue mass showing heterogeneous signal intensity in $\mathrm{T} 1$ and $\mathrm{T} 2 \mathrm{Wl}$, isointense to slightly faint high signal in DWI and mixed signals in ADC map. The mean ADC is $1.3 \times 10^{-3} \mathrm{~mm}^{2} / \mathrm{s}$ 

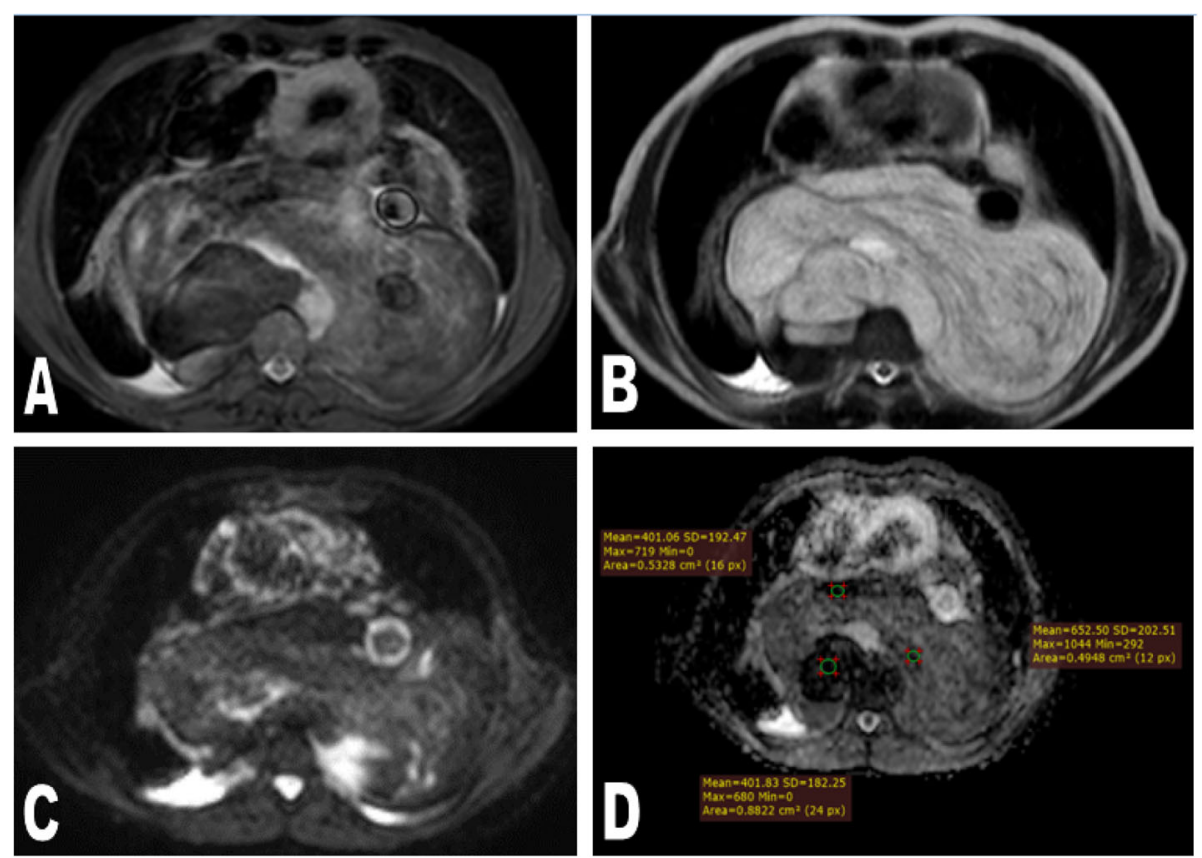

Fig. 6 Case of liposarcoma. A 60-year-old male patient presenting with progressive loss of weight, chest pain, and dyspnea. MRI chest (a) axial STIR, (b) axial T2, (c) DWI, and (d) ADC map: showing large posterior mediastinal mass of hyper intense signal on T2 WI, intermediate signal on STIR with patchy hyperintense areas on DWI, and low signal on ADC map (restricted diffusion). The mean ADC value was $0.5 \times 10^{-3} \mathrm{~mm}^{2} / \mathrm{s}$. Bilateral minimal pleural effusion is noted

\section{Discussion}

Depending only on the qualitative assessment of diffusion images to differentiate between benign and malignant masses is not sufficient, because some lesions can show atypical imaging features [8]. We had two malignant lesions with facilitated diffusion patterns; they were proved to be bronchogenic carcinoma and lymphoma. These false-negative results likely were attributed to presence of necrosis. In the study of El-Nahas M. et al. [8], there were three pathologically proved benign lesions with restricted diffusion pattern and two malignant lesions with facilitated diffusion pattern.

So in addition to the data obtained from conventional MRI, DWI enabled us to obtain more information derived from the microscopic motion of water protons. Also, quantitative tumor assessment is possible by the calculation of ADC, which is related to the proportion of extracellular and intracellular components [9].

The difference in the ADC value between malignant and benign tumors is explained by the difference in the histopathological features of benign and malignant tumors. Malignant tumors show hypercellularity and have enlarged nuclei, hyperchromatism, and angulation of nuclear contour. These reduce the extracellular matrix and the diffusion space of water protons in the extracellular and intracellular dimensions with a resultant decrease in ADCs [10].

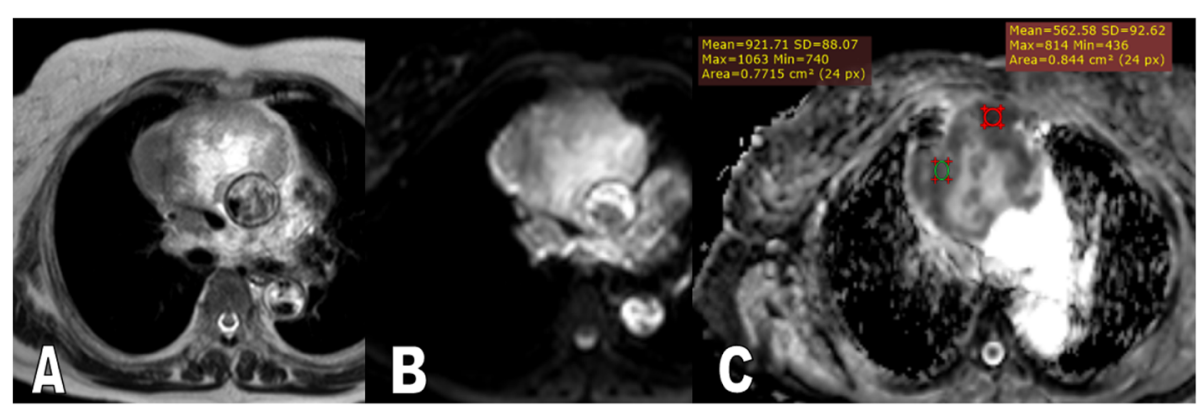

Fig. 7 Case of neuroendocrinal carcinoma. A 66-year-old female patient complaining of chest pain and weight loss. MRI chest (a) axial T2WI, (b) DWI, and (c) ADC map showing anterior mediastinal mass being hypointense on T2 Wl, showing restricted diffusion (high signal on DWI and low signal on ADC map) with a mean ADC value of $0.92 \times 10^{-3} \mathrm{~mm}^{2} / \mathrm{s}$ 
The study included 34 malignant cases (77.3\%) and 10 benign cases (22.7\%). We found that the mean ADC value of malignant mediastinal lesions was significantly lower than the mean ADC value of benign mediastinal lesions, with mean ADC $1.39 \pm 0.26$ in benign mediastinal lesions and mean ADC $0.86 \pm 0.35$ in malignant mediastinal lesions. This result agrees with the results of Nasr A. et al. [4], who reported that the mean ADC value for the malignant lesions was $0.91 \pm 0.23 \times 10^{-3}$ $\mathrm{mm}^{2} / \mathrm{s}$ while the mean ADC value for the benign lesions was $1.80 \pm 0.55 \times 10^{-3} \mathrm{~mm}^{2} / \mathrm{s}$. This study results are also consistent with the results of El-Nahas M. et al. [8], Dawood H.A., and Salah-Eldin M [9]., Abdel Razek A [11]., and Gümüștaș S. et al. [12].

In agreement with the results of Nasr A. et al. [4], Dawood H.A. and Salah-Eldin M., [9], and Tondo et al. [13], the results of our study demonstrated that the cutoff threshold of ADC value for the differentiation between malignant and benign lesion was $1.11 \times 10^{-3}$ $\mathrm{mm}^{2} / \mathrm{s}$, with an area under ROC curve of 0.93 . The sensitivity and specificity of our cutoff ADC values were $90.9 \%$ and $100 \%$, with $100 \%$ positive predictive value and $76.9 \%$ negative predictive value. However, Abdel Razek A [11]., Gümüştaş et al. [12], and Sabri Y. et al. [14] reported higher cutoff ADC values of $1.56 \times 10^{-3} \mathrm{~mm}^{2} / \mathrm{s}$, $1.39 \times 10^{-3} \mathrm{~mm}^{2} / \mathrm{s}$, and $1.4 \times 10^{-3} \mathrm{~mm}^{2} / \mathrm{s}$, respectively, for the discrimination between malignant and benign mediastinal lesions. This variation of cutoff ADC values is likely attributed to the discrepancy in the sample size and the MRI technique specially the use of different $b$ values.

The results of our study did not find a significant difference in the mean ADC value between lymphoma and other malignant tumors. This is concordant with the results of Nasr A. et al. [4], Gümüştaş et al. [12], and Abdel Razek A. et al. [10] who compared ADCs of lymphomas and bronchogenic carcinomas and there was no significant difference in their mean ADCs. But these results are discordant with the results of Sumi M. et al. [15], who found a significant difference in the mean ADC value between lymphoma and carcinoma. Also, Nomori et al. [16] reported that the ADCs of lymphomas were significantly smaller than those of carcinomas.

Our study involved the evaluation of 12 patients with malignant mediastinal/hilar lymphadenopathy in cases of central bronchogenic carcinoma, lymphoma, and metastatic breast cancer, which showed restricted diffusion, showing low ADC value with mean ADC value $(0.79+1$ $-0.32) \times 10^{-3} \mathrm{~mm}^{2} / \mathrm{s}$ (range $0.43-1.8$ ). This is concordant with the results of Abdel Razek A [11]., who reported that the metastatic lymph nodes are usually hypointense on the calculated ADC map with low ADC value $(1.01+/$ $\left.-0.02 \times 10^{-3} \mathrm{~mm}^{2} / \mathrm{s}\right)$. These are also similar to the results of Ustabasioglu F.E. et al. [17], Nakayama J. et al. [18], and Kosucu P. et al. [19], who reported that the mean ADC value in malignant lymph nodes is low, with mean $\left(1.030 \pm 0.245 \times 10^{-3} \mathrm{~mm}^{2} / \mathrm{s}\right),\left(0.24 \times 10^{-3} \mathrm{~mm}^{2} / \mathrm{s}\right)$, and $\left(1.012+/-0.025 \times 10^{-3} \mathrm{~mm}^{2} / \mathrm{s}\right)$ respectively.

Mediastinal lymphadenopathy that detected in our cases of central bronchogenic carcinoma, showed restricted diffusion with mean $\mathrm{ADC}$ value $0.70 \pm 0.26 \times$ $10^{-3} \mathrm{~mm}^{2} / \mathrm{s}$ (range $0.43-1.10$ ). In the study of Hasegawa et al. [20], who found that diffusion MR imaging can be used for the diagnosis of metastatic lymph nodes in patients with non-small cell lung carcinoma (NSCLC) with a high degree of accuracy (95\%).Whereas Nomori et al. [16] reported that the cutoff ADC value used to differentiate metastatic from non-metastatic lymph nodes in patients with NSCLC is $1.63 \times 10^{-3} \mathrm{~mm}^{2} / \mathrm{s}$, with an accuracy of $89 \%$.

The mean ADC value in lymphoma cases in this study was $0.84 \pm 0.43 \times 10^{-3} \mathrm{~mm}^{2} / \mathrm{s}$ (range 0.50-1.80). Most lymphomas are hypercellular, with enlarged nuclei and hyperchromatism, which result in a contracted extracellular space and decreased ADC. However, the ADC may be misleadingly elevated depending on differences between lymphoma types in cellularity, intracellular architecture, the presence and amount of necrosis, and perfusion [5]. This may explain why there is one case that showed elevated ADC value $1.8 \times 10^{-3} \mathrm{~mm}^{2} / \mathrm{s}$ with faint high signal in DWI and high signal in the ADC map. The case was non-Hodgkin lymphoma. Sumi et al. [15] and Sabri et al. [2] reported that the mean ADC value of lymphoma was $\left(0.454 \pm 0.075 \times 10^{-3} \mathrm{~mm}^{2} / \mathrm{s}\right)$ and $(1.22 \pm 0.23) \times 10^{-3} \mathrm{~mm}^{2} / \mathrm{s}$ respectively.

Grading of malignancy and differentiation of low from high-grade malignancy is essential for prognosis. In this study, there were only three undifferentiated malignant cases, when compared to other differentiated malignant cases, we found no significant difference in the mean $A D C$ value between both groups. This is discordant with the results of Abdel Razek A. et al. [10], who stated that there was a significant difference in the ADC value between well differentiated and poorly differentiated malignancy.

In our study, the mean ADC value for the only one adenocarcinoma case was not significantly higher than small cell lung cancer, which is also discordant to Abdel Razek A. et al. [10], who reported adenocarcinoma type of lung cancer revealed a high $\mathrm{ADC}$ value $\left(2.1 \times 10^{-3}\right.$ $\mathrm{mm}^{2} / \mathrm{s}$ ) that was mistaken as a benign tumor. Matoba et al. [21] reported that the mean ADC value of adenocarcinoma was significantly higher than that of squamous cell carcinoma and large cell carcinoma $(2.1 \times$ $10^{-3} \mathrm{~mm}^{2} / \mathrm{s}$ vs. $1.6 \times 10^{-3} \mathrm{~mm}^{2} / \mathrm{s}$ vs. $1.3 \times 10^{-3} \mathrm{~mm}^{2} / \mathrm{s}$, respectively). It was also reported that the mean ADC value of well-differentiated adenocarcinoma was 
significantly higher than the values for moderately and poorly differentiated squamous cell carcinoma and poorly differentiated adenocarcinoma. This finding is also supported by Mori et al. [22]. On the contrary, Koyama et al. [23] reported that quantitative DWI is less sensitive than STIR in the detection and subtype classification of pulmonary adenocarcinoma. Therefore, DWI should always be evaluated in conjunction with conventional MRI sequences.

The limitations of our study included the relatively small number of cases in general as well as in each pathological entity. Furthermore, the lack of sizeable comparative group using another functional imaging modality as 8F-FDG-PET/CT.

\section{Conclusion}

With the advances in MR systems, DWI of the chest has become possible with fast imaging time that reduces the effect of cardiac and respiration movement. DWI is a non-contrast functional MR imaging technique adding in the analysis of tissue characteristics based on the diffusion of water protons within the tissue. Quantitative assessment of a mediastinal mass is done by calculating its ADC value which is inversely correlated with tissue cellularity. So, DWI has diagnostic potential to distinguish benign from malignant tumors because of the tendency of the malignant lesions to show lower ADC values and more restricted diffusion.

\section{Abbreviations}

MRI: Magnetic resonance imaging; DWl: Diffusion-weighted imaging; ADC: Apparent diffusion coefficient; CT: Computed tomography; 18F-FDGPET/CT: 18F-Fluorodeoxiglucose positron emission tomography/CT; NSCL C: Non-small cell lung carcinoma; ROC: Receiver operating characteristic curve

\section{Acknowledgements}

The authors would like to thank all the personnel who contributed in this study.

\section{Authors' contributions}

TR shared in the study conception and design, acquisition of data, analysis and interpretation of data, and drafting of the manuscript. SM formulated the research goals, designed the study methodology, and supervised/actively participated in the research activity planning/execution. EM conducted/ actively participated in the research process, performed the data collection/ data analysis, and wrote the initial draft of the manuscript. HS shared in the study conception, design, and shared in writing and correcting the manuscript and revision. AS shared in correcting and reviewing the manuscript. All authors have read and approved the manuscript.

\section{Funding}

This research did not receive any specific grant from funding agencies in the public, commercial, or not-for-profit sectors. There were no sources of funding for this work other than departmental resources.

\section{Availability of data and materials}

The datasets used and/or analyzed during the current study is available from the corresponding author on reasonable request.

\section{Ethics approval and consent to participate}

This study was approved by the Research Ethics Committee of the National Cancer Institute, Cairo University. Ethics Committee reference number is not available (was not provided). Written informed consent was obtained from all the study patients before any data or scans were gathered or performed.

\section{Consent for publication}

All patients included in this research ( $\geq 18$ years of age) gave written informed consent to publish the data contained within this study. If the patient was unconscious when consent for publication was requested, written informed consent for the publication of data was given by his/her parent or legal guardian.

\section{Competing interests}

The authors declare that they have no competing interests.

\section{Author details}

${ }^{1}$ Radiology Department, National Cancer Institute-Cairo University, Giza, Egypt. ${ }^{2}$ Radiology Department, Faculty of Medicine (for girls), Al Azhar University, Cairo, Egypt. ${ }^{3}$ Department of Diagnostic and Interventional Radiology, Kasr Al Ainy Faculty of Medicine, Cairo University, Cairo, Egypt.

Received: 26 May 2020 Accepted: 10 September 2020

Published online: 21 September 2020

\section{References}

1. Carter, B. W., Betancourt, S. L., \& Benveniste, M. F. (2017). MR imaging of mediastinal masses. Top Magn Reson Imaging, 26(4), 153-165. https://doi. org/https://doi.org/10.1097/RMR.0000000000000134.

2. Sabri, Y.Y., Nossair, E.Z.B., Assal, H.H. et al. Role of diffusion weighted MRimaging in the evaluation of malignant mediastinal lesions (2020). Egypt J Radiol Nucl Med 51, 32. https://doi.org/https://doi.org/10.1186/s43055-0200132-6

3. Broncano, J., Alvarado-Benavides, A. M., Bhalla, S., Álvarez-Kindelan, A., Raptis, C. A., \& Luna, A. (2019). Role of advanced magnetic resonance imaging in the assessment of malignancies of the mediastinum. World J Radiol, 11(3), 27-45. https://doi.org/https://doi.org/10.4329/wjr.v11.i3.27

4. Nasr A., Elshahat H., Safwat H., Alsaif R., Alshehab D., Shebl M (2016). Diffusion weighted MRI of mediastinal masses: can measurement of ADC value help in the differentiation between benign and malignant lesions. Egypt J Radiol Nucl Med 47, 119-125. https://doi.org/https://doi.org/10. 1016/j.ejrnm.2015.12.002

5. Gümüştaş S, Inan N, Akansel G, Başyĭğït I, Ciftçi E (2013) Differentiation of lymphoma versus sarcoidosis in the setting of mediastinal-hilar lymphadenopathy: assessment with diffusion-weighted MR imaging. Sarcoidosis Vasc Diffuse Lung Dis 30(1):52-59. 24003535

6. B. Türkbey, O. Aras, N. Karabulut, et al. (2012). Diffusion-weighted MRI for detecting and monitoring cancer: a review of current applications in body imaging. Diagn Interv Radiol, 18, pp. 46-59. https://doi.org/https://doi.org/ 10.4261/1305-3825.dir.4708-11.2

7. Nakayama J, Miyasaka K, Omatsu T, Onodera Y, Terae S, Matsuna Y, Cho Y (2010). Metastases in mediastinal and hilar lymph nodes in patients with non-small cell lung cancer: quantitative assessment with diffusion weighted magnetic resonance imaging and apparent diffusion coefficient. J Comput Assist Tomogr 34:1-8. https://doi.org/https://doi.org/10.1097/rct. 0b013e3181a9cc07

8. El-Nahas M, Sadek A, Gwely N, Elrakhawy M, Al-Naghy E (2018). MR diffusion imaging and ADC measurement in solid and cystic mediastinal masses for differentiating benign from malignant lesions, Egypt J Radiol Nucl Med, 49, 976-985, https://doi.org/https://doi.org/10.1016/j.ejrnm.2018.06.004.

9. Dawood HA, Salah-EIDin M (2014) Role of MRI apparent diffusion coefficient quantification in the differentiation between benign and malignant mediastinal and pulmonary lesions. Med J Cairo Univ 82(2):153-158

10. Abdel Razek A., Elmorsy A., Elshafey M., Elhadedy T., and Hamza O. (2009). Assessment of mediastinal tumors with diffusion weighted single-shot echo-planar MRI, journal of magnetic resonance imaging 30:535-540. https://doi.org/https://doi.org/10.1002/jmri.21871

11. Abdel Razek A. (2012). Diffusion MRI of chest tumors, Cancer Imaging, 12: 452-463. https://dx.doi.org/https://doi.org/10.1102/1470-7330.2012.0041

12. Gümüştaş S, Inan N, Sarisoy HT, Anik Y, Arslan A, Çiftçi E, Akansel G, Demirci A (2011) Malignant versus benign mediastinal lesions: quantitative 
assessment with diffusion weighted MR imaging. Eur Radiol 21(11):22552260. https://doi.org/10.1007/s00330-011-2180-9

13. Tondo F., Saponaro A., Stecco A., Lombardi M., Casadio C., Carriero A. (2011). Role of diffusion-weighted imaging in the differential diagnosis of benign and malignant lesions of the chest-mediastinum, Radiol Med, 116:720-733. https://doi.org/https://doi.org/10.1007/s11547-011-0629-1

14. Sabri YY, Taymour T, Khairy M, Moawad M, Khafagy H (2017) Role of MRI diffusion in assessment of malignant mediastinal masses. Med J Cairo Univ 85(4):1497-1504

15. Sumi M., Ichikawa Y., Nakamura T. (2007). Diagnostic ability of apparent diffusion coefficients for lymphomas and carcinomas in the pharynx, EurRadiol, 17: 2631-2637. https://doi.org/10.1007/s00330-007-0588-z

16. Nomori H, Mori T, Iked AK (2008) Diffusion weighted magnetic resonance imaging can be used in place of positron emission tomography for $\mathrm{N}$ staging of non-small cell lung cancer with fewer false-positive results. J Thoracic Cardiovascular Surg 135:816-822. https://doi.org/10.1016/j.jtcvs. 2007.10.035

17. Ustabasioglu, F. E., Samanci, C., Alis, D., Samanci, N. S., Kula, O., \& Olgun, D. C. (2017). Apparent diffusion coefficient measurement in mediastinal lymphadenopathies: differentiation between benign and malignant lesions. J Clin Imaging Sci, 7, 12. https://doi.org/https://doi.org/10.4103/jicis.JCIS_84_16

18. Nakayama J, Miyasaka K, Omatsu T, Onodera Y, Terae S, Matsuna Y, Cho Y (2010) Metastases in mediastinal and hilar lymph nodes in patients with non-small cell lung cancer: quantitative assessment with diffusion weighted magnetic resonance imaging and apparent diffusion coefficient. J Comput Assist Tomogr 34:1-8. https://doi.org/10.1097/RCT.0b013e3181a9cc07

19. Kosucu P. , Tekinbas C., Erol M., Sari A., Kavgaci H., Oztuna F., Ersoz S., (2009). Mediastinal lymph nodes: assessment with diffusion-weighted MR imaging, J Magn Reson Imaging, 30:292-297. https://doi.org/https://doi.org/10.1002/ jmri.21850

20. Hasegawa I, Boiselle P, Kuwabara K et al (2008) Mediastinal lymph nodes in patients with non-small cell lung cancer: preliminary experience with diffusion weighted MR imaging. J Thoracic Imaging 23:157-161. https://doi. org/10.1097/RTI.0b013e318166d2f5

21. Matoba M, Tonami H, Kondou T, (2007). Lung carcinoma: diffusion-weighted MR imaging preliminary evaluation with apparent diffusion coefficient. Radiology; 243:570-577. https://doi.org/https://doi.org/10.1148/radiol. 2432060131

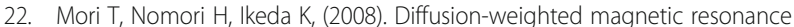
imaging for diagnosing malignant pulmonary nodules/masses: comparison with positron emission tomography. J ThoracOncol; 3:358-364. https://doi. org/https://doi.org/10.1097/jto.0b013e318168d9ed

23. Koyama H, Ohno Y, Aoyama N (2010) Comparison of STIR turbo SE imaging and diffusion-weighted imaging of the lung: capability for detection and subtype classification of pulmonary adenocarcinomas. EurRadiol 20:790-800. https://doi.org/10.1007/s00330-009-1615-z

\section{Publisher's Note}

Springer Nature remains neutral with regard to jurisdictional claims in published maps and institutional affiliations.

\section{Submit your manuscript to a SpringerOpen ${ }^{\circ}$ journal and benefit from:}

- Convenient online submission

- Rigorous peer review

- Open access: articles freely available online

- High visibility within the field

- Retaining the copyright to your article

Submit your next manuscript at $\boldsymbol{\nabla}$ springeropen.com 